\title{
The Long-Term (1964-2014) Variability of Aerosol Optical Thickness and its Impact on Solar Irradiance Based on the Data Taken at Belsk, Poland
}

\author{
Michał POSYNIAK, Artur SZKOP, Aleksander PIETRUCZUK, \\ Jerzy PODGÓRSKI, and Janusz KRZYŚCIN \\ Institute of Geophysics, Polish Academy of Sciences, Warszawa, Poland \\ e-mail: alek@igf.edu.pl
}

\begin{abstract}
Measurements of the Linke turbidity factor (LTF) were performed at Belsk $\left(20.78^{\circ} \mathrm{E}, 51.83^{\circ} \mathrm{N}\right)$, Poland, since 1964 . This data is used to retrieve broadband aerosol optical thickness normalized to the air mass equal to 2 (BAOT2). A linear analysis of the BAOT2 changes reveals an upward trend of $0.023 \pm 0.017(2 \sigma)$ in the $1964-1975$ period, a downward trend of $-0.051 \pm 0.017(2 \sigma)$ in the 1976-1991 period, and afterwards a statistically insignificant trend of $-0.009 \pm 0.014(2 \sigma)$. Such pattern may be related to the economic changes in Poland (changing emissions and environmental policies). The elevated BAOT2 values, excluded from the trend, are found in 1984 and 1992 due to the volcanic eruptions of El Chichon and Mt. Pinatubo, respectively. Past AOT values at 340 and $500 \mathrm{~nm}$ are reconstructed using a linear relationship found between AOT and BAOT2. The reconstructed data is used by the radiative transfer models to estimate a response of the total solar and erythemal radiation to the changes in the atmospheric aerosols at Belsk.
\end{abstract}

Key words: Linke turbidity factor, aerosol optical thickness, data reconstruction, trend. 


\section{INTRODUCTION}

The aerosol's impact on the climate is still one of the most uncertain aspects in the atmospheric science (IPCC 2013). These uncertainties are caused mainly by the large spatial-temporal variability of the atmospheric aerosols. The aerosol optical properties are widely studied by the ground-based networks, for example AERONET (Aerosol Robotic Network) (Holben et al. 1998) and satellite based instruments (King et al. 1999, Kaufman et al. 2002, Mishchenko et al. 2007). The recent instrumentation development has allowed for almost complete coverage of the globe with remote aerosol observations. However, continuous observations over several decades are rather rare.

The first direct and automated aerosol optical thickness (AOT) measurements in Europe started in 1986 at Lindenberg station, Germany (Weller and Leiterer 1988). The lack of earlier AOT data poses a significant difficulty for the performing of a reliable trend analysis (Zhao et al. 2008). Some attempts were undertaken in the recent years to reconstruct past AOT values based on the archived solar irradiance data. Streets et al. (2009) carried out a wide study of the long-term solar irradiance, from NCAR and GEBA data base, to show the so-called "dimming-brightening transition" around 1980. They attributed the brightening to the decrease of the anthropogenic aerosol emissions and possibly to the increase in precipitation, especially in Europe. The model calculations showed the AOT trend of about $-1 \%$ per year for Western Europe in the period 1980-2006 (Stanhill and Cohen 2001, Wild 2008). Similarly, Ruckstuhl et al. (2008) found the AOT decrease of up to $-3 \%$ per year at Zingst and Lindenberg stations (Germany) in the 1986-2005 period. While the local AOT trend seems to be slightly negative, this is not the case for the developing counties in Eastern and Southern Asia, and in Africa (Streets et al. 2009).

Various retrievals of the atmospheric parameters were proposed throughout the years with a considerable amount of data being obtained and recorded. Linke (1922) proposed a measurement of the broadband (over the whole solar spectrum, 300-3000 nm) aerosol index, the so-called Linke turbidity factor (LTF), to be carried out in perfect clear-sky conditions. In Poland continuous LTF measurements have been performed since 1964 at Belsk $\left(20.8^{\circ} \mathrm{E}, 51.8^{\circ} \mathrm{N}\right)$ (Michałowska-Smak 1981) and on Mt. Kasprowy Wierch (1987 m a.s.1.) in Southern Poland (Uscka-Kowalkowska 2013, Markowicz and Uscka-Kowalkowska 2015).

In this work the complete set of the aerosol data from the Belsk's observatory is analysed for the long-term AOT variability including: the broad band (300-3000 nm) AOT (BAOT) retrieved from the LTF pyrheliometric measurements (1964-2014). In addition, AOTs at 340 and at $500 \mathrm{~nm}$, derived from the direct-sun observations by the CIMEL sun photometer obser- 
vations (2002-2012), are also analysed. A reconstruction of AOT at 340 and $500 \mathrm{~nm}$ dating back to January 1964 is performed using a linear relationship between broadband aerosol optical thickness normalized to the air mass of 2 (BAOT2), which is retrieved from LTF and water vapour pressure measurements at the ground level, and the Cimel AOT values from simultaneous observations in the period 2002-2012. The reconstructed AOT yearly means are used for trend analyses in the period 1964-2014.

The reconstructed AOTs at $340 \mathrm{~nm}$ allows to estimate an impact of the long-term AOT changes on the surface UV levels at Belsk. Thinning of the ozone layer, caused by the anthropogenic emission of the ozone-depleting gases (e.g., freons, halons), has appeared to be one of the most concerning ecological issues since the discovery of the Antarctic ozone hole in the mid1980s (Chubachi 1984, Farman et al. 1985). A depleted ozone layer was also found over Belsk (Krzyścin et al. 2013). Here an impact of the long-term AOT changes on the surface UV level at Belsk will be estimated. Reconstructed AOTs at $500 \mathrm{~nm}$ will also be used to estimate the direct effect of the aerosols, including both the scattering and the absorption of the radiation. The direct aerosol effects are calculated for the estimation of the long term (1970-2010) change in the broadband solar energy flux at the Belsk station. The long-term aerosol effects on the surface total solar radiation and its UV part are calculated using the radiative transfer model simulations with the reconstructed AOT taken as the model input.

\section{METHODS AND INSTRUMENTATION}

The Belsk observatory $\left(51.83^{\circ} \mathrm{N}, 20.78^{\circ} \mathrm{E}\right)$ is located in a rural area around $50 \mathrm{~km}$ south of Warsaw. The observatory is equipped with various instruments used for the measurement of the aerosol optical properties. A number of Sonntag pyrheliometers were used at Belsk to determine LTF values at the air mass $m, T_{L, m}$, (IGY 1958) since 1964 and the data were published in the series of the Belsk's data annals (Michałowska-Smak 1981).

The CIMEL sun photometer has been operating in Belsk since 2002 as part of the AERONET. The instrument provides AOT values at several wavelengths as well as the total (in the whole vertical column of the atmosphere) precipitable water vapour (TPWV) content (Holben et al. 1998).

$T_{L, m}$ represents a number of atmospheres containing neither aerosols nor water vapour that causes the same attenuation of total (over the whole solar spectrum) solar irradiance as that by the real atmosphere. The factor is typically calculated using the following formula (Grenier et al. 1994):

$$
T_{L, m}=\frac{1}{\delta_{R, m} m} \ln \frac{I_{0}}{I_{M}}
$$


where $\delta_{R, m}$ is the optical thickness of aerosol free and dry atmosphere, $m$ is the optical mass, $I_{0}$ is the solar constant (corrected by the eccentricity factor), and $I_{m}$ is the direct solar irradiance. The optical thickness of the aerosol free and dry atmosphere is obtained from the formula by Grenier et al. (1994):

$$
\delta_{R . m}=\left(5.4729+3.0312 m-0.6329 m^{2}+0,0910 m^{3}+0.00512 m^{4}\right)^{-1} .
$$

A generally accepted practice is to reduce broadband characteristics of the transparency or turbidity from the actual optical air mass $m$ to the standard air mass, $m=2$ (Ohvril et al. 2009).

$$
p_{m}=e^{-\delta_{R, m} T_{L, m}}
$$

next it is reduced to air mass equal to 2 as follows:

$$
p_{2}=p_{m}\left(\frac{2}{m}\right)^{\frac{\log p_{m}+0,009}{\log m-1.1848}}
$$

The atmospheric integral transparency coefficient provides the Linke turbidity $T_{L, 2}$ equal to (Ohvril et al. 1999):

$$
T_{L, 2}=-23 \log p_{2} .
$$

To calculate broadband aerosol thickness at air mass equal to 2 (BAOT2) we use the formula:

$$
\mathrm{BAOT} 2=\delta_{R, 2} T_{L, 2}-\delta_{R, 2}-\delta_{W, 2}
$$

where $\delta_{R, 2}$ denotes optical thickness of the aerosol free and dry atmosphere at $m=2$ and $\delta_{W, 2}$ is broadband optical thickness of water vapour (Kannel et al. 2012)

$$
\delta_{W, 2}=-\frac{1}{2} \ln \left(1-0.137 w^{0.32}\right)
$$

where $w$ is TPWV $[\mathrm{cm}]$ content measured at the Belsk observatory by the CIMEL sun photometer since 2002.

The standard least-squares fitting of $w$ (in $\mathrm{cm}$ ) on the surface water vapour pressure $e$ (in $\mathrm{hPa}$ ) is used to reconstruct the values of $w$ before 2002 based on $e$ values taken during routine meteorological observations at the station.

Linear regression is performed for both the warm and cold parts of the year to obtain the following formulas:

$$
w=-0.114+0.143 e
$$

for warm half-year (April-September), and 


$$
w=-0.006+0.123 e
$$

for cold half-year (October-March).

Previously published data from Belsk were elaborated with the method presented by Michalowska-Smak (1981). Here $T_{L, 2}$ is directly calculated from formula 1. However, there are some gaps in the Belsk's data archives. These are filled up with the $T_{L, 2}$ data published in the Belsk's data annals after being recalculated and homogenized using the data from the direct sun measurements.

\section{UNCERTAINTIES ANALYSIS}

Firstly, a systematic error resulting from the reduction of the actual air mass, under which the measurements were performed, to the standardized value of 2 must be taken into account. The uncertainties grow as the air mass deviates from this standardized value. The minimum theoretical value of air mass at Belsk is $\sim 1.14$ (corresponding to the Sun's highest position in the sky during the summer solstice) while in this study only the measurements with the air mass below 3 were analyzed. The resulting relative uncertainties remain in the vicinity of $10 \%$ in both the ends of this interval.

The main source of BAOT2 uncertainties originates from the direct solar flux measurement errors. According to Markowicz and Uscka-Kowalkowska (2015), the uncertainties are largest for low optical thicknesses and small air masses. In the case of BAOT2 of 0.05 and air mass near 1, the absolute uncertainty reaches 0.025 or $50 \%$ in the relative terms. On the other hand, for a moderately high BAOT 2 of 0.25 and the air mass of 3 the uncertainty falls approximately to $3 \%$.

Sonntag pyrheliometers have a field of view (FOW) of approximately $10.2^{\circ}$. The diffused solar radiation entering the detector leads to a slight underestimation of the measured BAOT2. The effect is usually small and only becomes significant for large AOD values measured under high optical mass, especially in the presence of large aerosol particles (Box and Deepak 1978). Under these conditions the resulting uncertainty is approximately $10 \%$.

Another contribution to the BAOT2 uncertainties is due to the TPWV retrievals (Eqs. 8 and 9) as the water vapour absorbs strongly in the infrared part of electromagnetic spectrum. Once again the resulting uncertainties change with the BAOT2 and air mass reaching relative values between 1.5 and $13 \%$.

The total uncertainties of the BAOT2 retrievals were calculated from the exact differential of Eq. 6 . Under moderate conditions of BAOT2 $\sim 0.15$ and $m \sim 2$, corresponding to the majority of the studied cases, the uncertainties remain below $20 \%$. However, the relative errors become larger as the broad- 
band optical depth and the air mass decreases. In the extreme case of a very low BAOT of 0.05 measured under optical mass of 1.14 , the uncertainty may reach $80 \%$.

\section{BROADBAND AEROSOL OPTICAL THICKNESS}

Time series of the annually averaged BAOT2 for the 1964-2014 period is presented in Fig. 1. The BAOT2 daily values are obtained using the formulas 1-9 from LTF and surface water vapour pressure measurements. For each year, the monthly means are calculated by averaging the BAOT2 values, next the yearly mean is obtained from the monthly means. The yearly values of BAOT2, shown as the grey squares in Fig. 1, are approximated using Belsk's data annals.

The BOAT2 measurements for the air mass of less than 3 are taken for calculation of the annual averages. Thus the measurements in December are omitted from the averages. Moreover, the January and February data are not considered, as clear-sky conditions happened only during the Arctic air mass advection resulting in an underestimation of the BOAT2 values for those months. Lack of the data for any other months permits calculation of the yearly (March-November) means as there is no statistically significant seasonal BOAT2 pattern (see Fig. 2).

The standard least-squares fit to the parts of the yearly BAOT2 time series reveals the following trends: a slight upward trend of $0.023 \pm 0.017(2 \sigma)$ per 10 years in the period of 1964-1975, next a strong downward trend of $-0.051 \pm 0.017(2 \sigma)$ per 10 years in the period 1976-1991, and a levelling off afterwards with statistically insignificant slope of $-0.009 \pm 0.014(2 \sigma)$ per 10 years. Years affected by volcanic eruptions El Chichón (in 1982) and

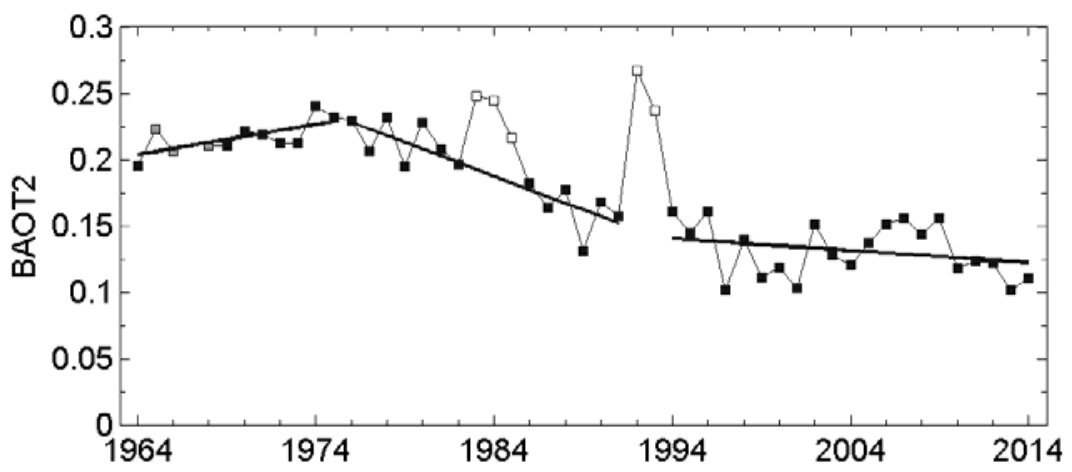

Fig. 1. The annual means of BAOT2 (squares). Straight lines are the least-squares regression lines, for the period 1964-1975, 1976-1991, and 1994-2013. Yearly values, shown as the grey squares, are the recalculated values published in Belsk's data annals. 


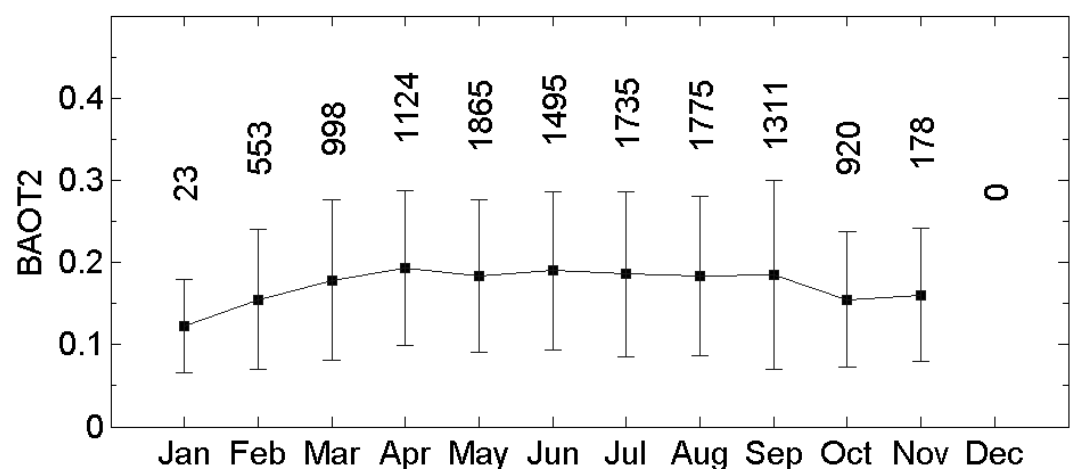

Fig. 2. Annual variability of BAOT2 based on the measurements for air mass less than 3. Error bars corresponds to standard deviations. Numbers above the points correspond to the number of analyzed cases in each month.

Mt. Pinatubo (in 1991), shown as open squares in Fig. 1, are omitted from the trend calculations.

Variability of the BAOT2 long-term pattern at Belsk is somewhat different than that reported for the former Soviet Union stations (Ohvril et al. 2009). The main difference is in the inflection point, which is in the mid1970s in case of Belsk and in the mid-1980s in case of most the former Soviet Union stations. However, the BOAT2 variability in Moscow is similar to that found at Belsk. Ohvril et al. (2009) explained it as an effect of Gorbachev's reform and a subsequent collapse of the former Soviet Union resulting in reduction of the aerosols emission. In our opinion, pattern of BAOT2 changes at Belsk reflects overall trends in the aerosols emission in Europe modified by the specific trends due to the changes in the Polish economy.

Upward trend up to 1980 was found by Michałowska-Smak (1981) in the data taken at Belsk and in Warsaw. In case of Belsk, a lowering of the trend could be visible in second part of the 1970s. However in Warsaw, upward trend is visible up to the end of 1980. The rural stations like Belsk are mainly affected by distant aerosol sources due to the big cities and/or heavy industry air contamination (Pietruczuk and Chaikovsky 2012, Pietruczuk 2013). The amount of this kind of aerosol could be related to the emission of the carbon and sulphates to the atmosphere. Both species are produced during the consumption of fossil fuels by industry, transport and domestic heating. Peak in sulphates emission is reported in the mid-1970s for both the western and the eastern part of Europe (Stern 2005). However, in the case of Eastern Europe, additional secondary peak in mid-1908s is also reported. Black Carbon (BC) emission has a peak in the 1970s in the case of most of the western European countries, but in the late 1970s over the former Soviet 
Union (Junker and Liousse 2008). Both peaks in BC and sulphates emission are coincident with start of lowering trend of BAOT2 at Belsk, which is enhanced by a slowing down of the Polish economy since mid-1970s, and a prolonged economic crisis in the 1980s and up to the beginning of the 1990s.

\section{RECONSTRUCTED AOT AT 340 AND 500 NM}

Figure 3 illustrates a linear relationship between BAOT2 and AOT (at 340 and at $500 \mathrm{~nm}$, respectively). AOT data was taken from the CIMEL sun photometer level 2.0 post calibrated dataset.

Kannel et al. (2012) suggested that relationship between AOTs and BAOT2 should be parabolic but in our case a linear fit seems also to be a good approximation. Here it appears that both variables have a linear relationship. The squared value of the correlation coefficient $\left(R^{2}\right)$ is around 0.7 in both cases. Thus, the linear regression formula of AOT at 340 and at $500 \mathrm{~nm}$ on BAOT2 could be used to reconstruct the spectral AOT time series back to the beginning of LTF observations. The following formulas are implemented for searching of past AOT values:

$$
\begin{aligned}
& \mathrm{AOT}_{340}=(2.1 \pm 0.1) \mathrm{BAOT} 2+(0.029 \pm 0.042), \\
& \mathrm{AOT}_{500}=(1.4 \pm 0.04) \mathrm{BOAT} 2+(0.002 \pm 0.032) .
\end{aligned}
$$

Figure 4 depicts a time series of the annual means of the reconstructed AOTs at 340 and $500 \mathrm{~nm}$ as well as AOTs measured by CIMEL Sun-photometer. CIMEL's annual means are calculated using all available values and the same method as in case BAOT2. Note that observed and reconstructed data agree very well, as $R^{2}$ is around 0.8 in both cases.
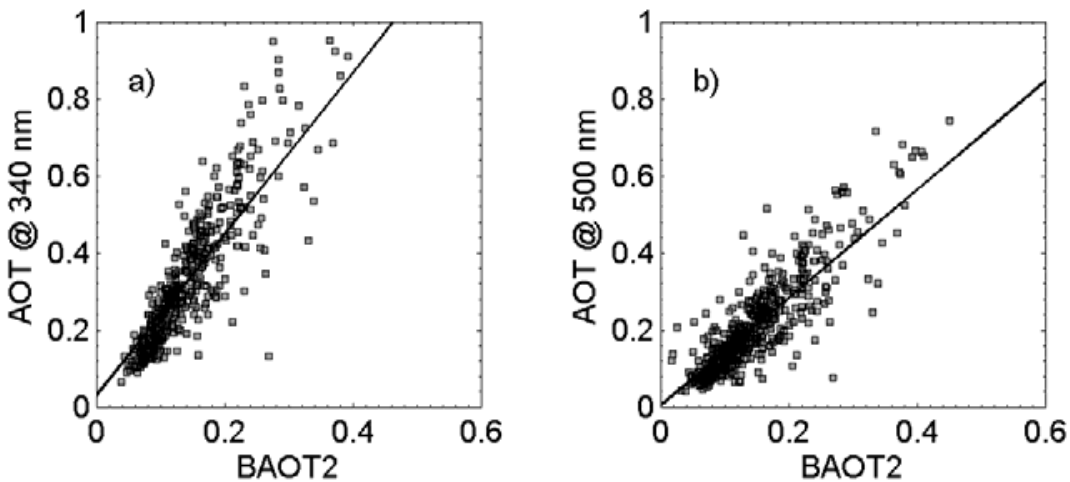

Fig. 3. The daily mean AOT at $340 \mathrm{~nm}$ (a) and at $500 \mathrm{~nm}$ (b) from the CIMEL sunphotometer measurements versus the corresponding BAOT2 values for the period 2002-2012. The straight line represents the least-squares linear fit to the scattered points. 

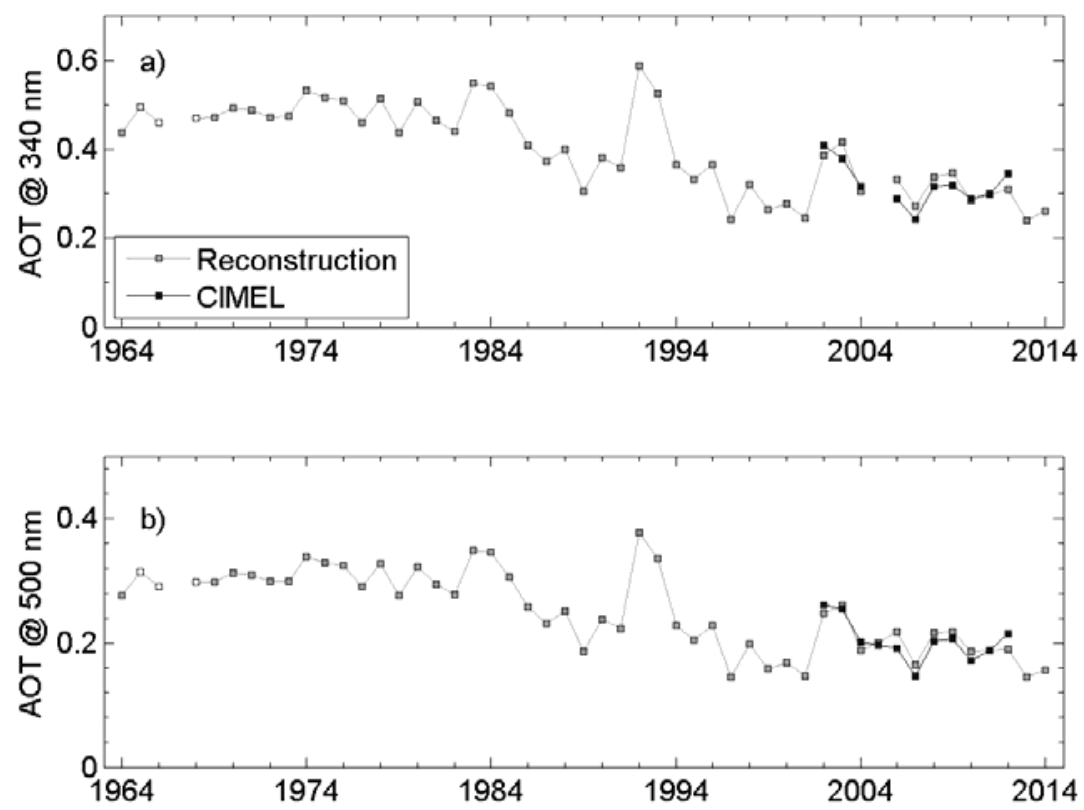

Fig. 4. Reconstructed annual means (grey squares) of AOT at $340 \mathrm{~nm}$ (a) and $500 \mathrm{~nm}$ (b) for the period 1964-2014 derived from BAOT2. The corresponding annual means based on the CIMEL spectral AOT observations are denoted by black squares. Yearly values, shown as open squares, are the recalculated values published in the Belsk's data annals.

Annual AOT means show a declining tendency since the mid-1970s up to about the mid-1990s and subsequent levelling off. Two local AOT maxima ( 1984 and 1992), which are forced by the large volcanic eruptions of El Chichon and Mt. Pinatubo, are clearly seen. It seems that the long-term variability of atmospheric aerosols significantly influenced solar radiation reaching the Earth's surface. The reconstructed AOT values at 340 and at $500 \mathrm{~nm}$ are used as input values of radiation transfer model, to reconstruct solar irradiances back to the mid-1960s at Belsk in the UV range and in the whole $(\sim 300-3000 \mathrm{~nm})$ solar range, respectively.

\section{THE AEROSOL EFFECTS ON SURFACE UV}

The decreasing AOT at Belsk may cause an increase of the UV-B (290$315 \mathrm{~nm}$ ) flux at the ground-level. To compare the ozone and aerosol forcings on the surface UV we calculate the so-called UV index (UVI, i.e., daily maximum of the erythemally weighted irradiance) in the period 1964-2014 for clear-sky conditions using the observed values of total ozone (by the 
Belsk's Dobson spectrophotometer) and the reconstructed AOT at $340 \mathrm{~nm}$ (see previous section).

The erythemally weighted irradiances at the Belsk's noon for clear-sky conditions are obtained from the radiative transfer (RT) calculations by the TUV model ver. 4 (source code available at web page http://cprm.acd.ucar. edu/Models/TUV) using daily values of total ozone and AOT at $340 \mathrm{~nm}$ as the model's input values. The fixed values of the single scattering albedo (SSA) of 0.94 , ground albedo of 0.03 , and the asymmetry factor (AF) of 0.70 are assumed. SSA and AF values are calculated at $441 \mathrm{~nm}$ wavelength averaging the AERONET data for Belsk. These value are used for the whole UV range $(290-400 \mathrm{~nm})$. It seems possible that SSA and AF depend on a wavelength and exhibit long-term variations, but here we would like to delineate an impact of only AOT changes on the UVI in the period 1964-2014. The AOT at $340 \mathrm{~nm}$ is representative for the UV wavelengths decisive for the erythemal irradiance $(\sim 310 \mathrm{~nm})$ as Jarosławski et al. (2003) show that the Ångström coefficient is approximately zero for the range $340-310 \mathrm{~nm}$ (see their Fig. 6b). Constant ground albedo of 0.03 in the UV range is typical for snowless surfaces (Blumthaler and Ambach 1988) excluding deserts or salt flats and thus this value has been used in many surface UV simulations (e.g., Degünther et al. 1998).

The RT calculations are made for days when both the ozone and aerosol data are available. Figure 5 shows the long-term (1964-2014) total ozone variability with a decline of $\sim 5 \%$ in the period 1980-1995 and the stabiliza-

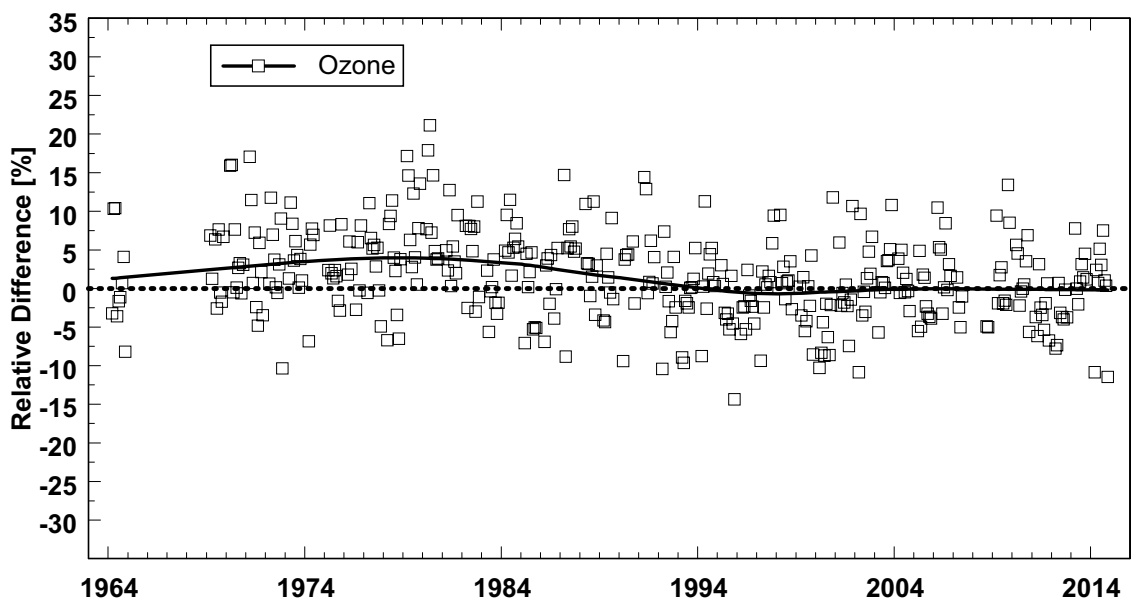

Fig. 5. The monthly (March-November) fractional deviations (open squares) of total ozone measured at Belsk in the period 1964-2014 and the pertaining smoothed values by LOWES smoother (black curve). The monthly means of total ozone are calculated, averaging daily values for days with BOAT2 measurements. 
tion afterwards. Next, the monthly mean UVI values are obtained by averageing the daily data. We consider the monthly means for the MarchNovember period, as it was previously performed in the case of the BOAT2 yearly data.

Two time series of the UV index for the period 1964-2014 are calculated assuming the following RT input: (i) actual daily values of total ozone and reconstructed AOT at $340 \mathrm{~nm}$, (ii) actual daily values of total ozone and fixed AOT at $340 \mathrm{~nm}$ value, 0.33 being the long-term (2000-2014) AOT mean for the March-November period. Next, the monthly fractional difference is obtained by subtracting the long-term (2000-2014) monthly mean UV index from the actual monthly mean UV index. This difference is expressed as a percentage of the long-term means.

Figure 6 shows both time series of the monthly fractional differences. The long-term variability of the combined aerosol and ozone forcing on the surface UV could be inferred from the smoothed pattern of the fractional differences by the RT model with (i) input. The UV response to the ozone forcing is derived from the fractional differences obtained by the RT model simsimulations using (ii) input. It is visible that the two curves are different in the period 1964-1996, suggesting a strong aerosol forcing on the surface UV field in that period. Figure 7 presents the difference between the former and the latter time series of the UV index fractional differences. The aerosols

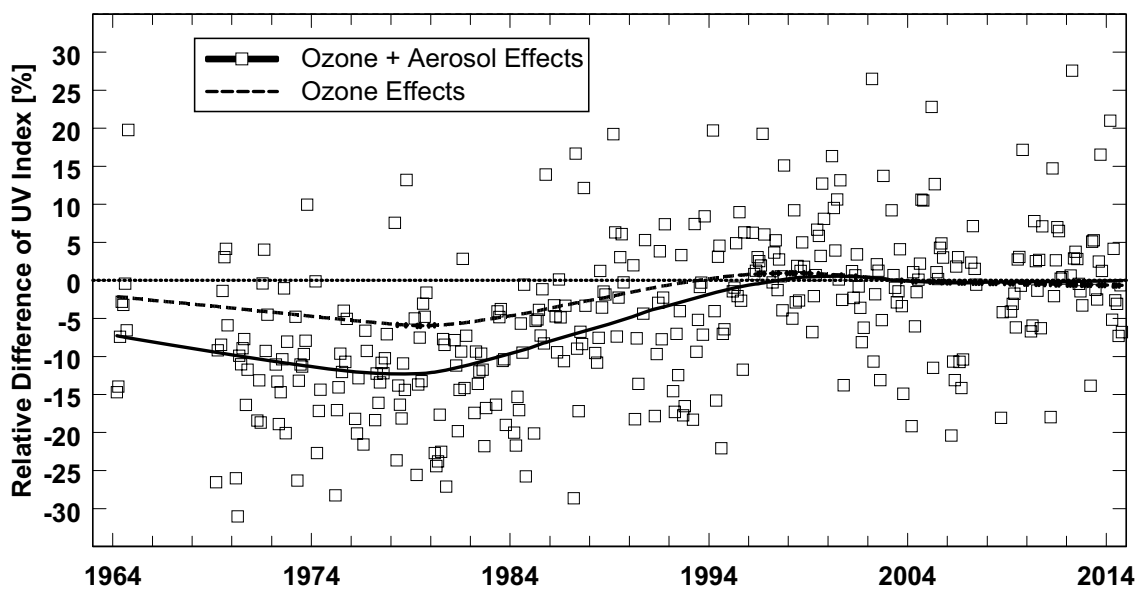

Fig. 6. The RT modelled monthly (March-November) fractional deviations (open squares) of UV index for the period 1964-2014 and the pertaining smoothed values by LOWES smoother (solid curve) with actual values of total ozone and the reconstructed AOT at $340 \mathrm{~nm}$. The dashed curve represents the smoothed values of the fractional differences by the RT model with actual values of total ozone and fixed AOT at $340 \mathrm{~nm}$. 


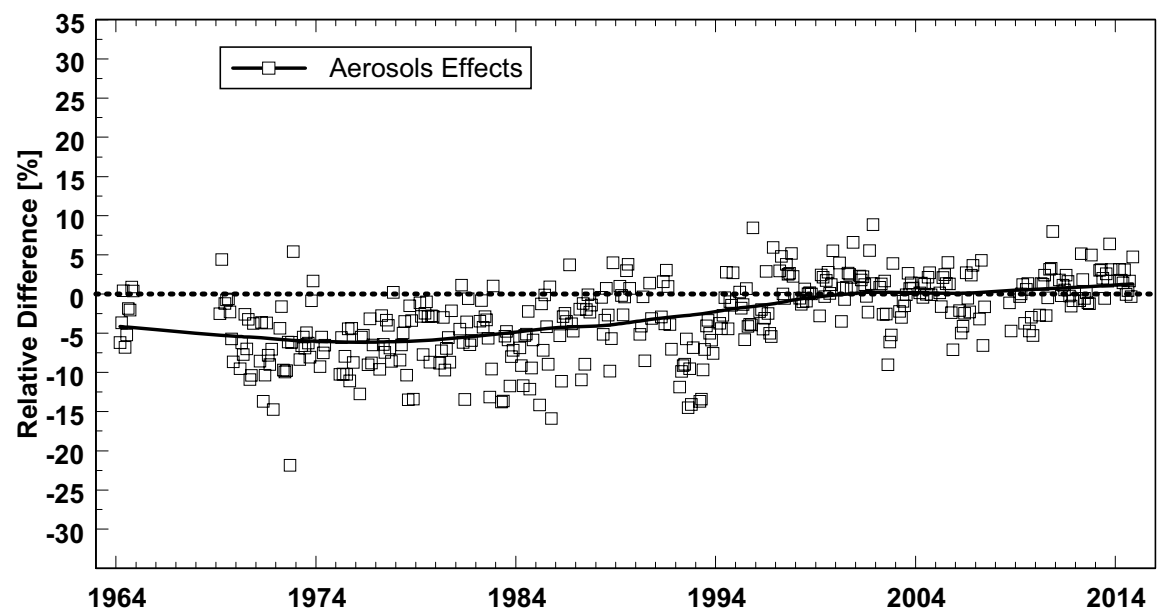

Fig. 7. The differences (open squares) between the monthly fractional differences by the RT simulations with actual values of total ozone and reconstructed AOT at $340 \mathrm{~nm}$ and those obtained with actual total ozone and fixed AOT at $340 \mathrm{~nm}$. The solid curve represents pertaining smoothed values by LOWES smoother.

force the maximum UV index decline of $6 \%$ in the mid-1970s and the trend of about $\sim 3 \%$ per decade in the period 1974-1996, that is comparable with the trend due to total ozone in that period (see dashed curve in Fig. 6).

It is seen that the total ozone and the aerosol changes had almost equal impact on the UV Index, both resulting in $\sim 5-6 \%$ increase in the period 1974-1996. It seems that a continuation of increasing UV tendency for clearsky conditions will be unlikely in the next decades as the atmospheric ozone started to recover over extratropical regions since the end of the $1990 \mathrm{~s}$ (WMO 2011) and no further cleaning of the atmosphere from the industrial aerosols is expected, as the Polish economy has started to recover in the recent years.

\section{THE AEROSOL EFFECTS ON TOTAL SOLAR RADIATION}

Changes of AOT at Belsk may result in the changes of the total solar radiation reaching the ground-level (Jarosławski et al. 2003, Jarosławski and Krzyścin 2005). Simplified radiative transfer model by Bird and Riordan (1986) is used with the input data including reconstructed AOT at $500 \mathrm{~nm}$ and water vapour content series as well as total ozone from the Dobson spectrophotometer. Additional physical parameters characterizing aerosols are required by the model. These are set based on averaged values from the Belsk station (taken from AERONET database for 2002-2010 period). The 


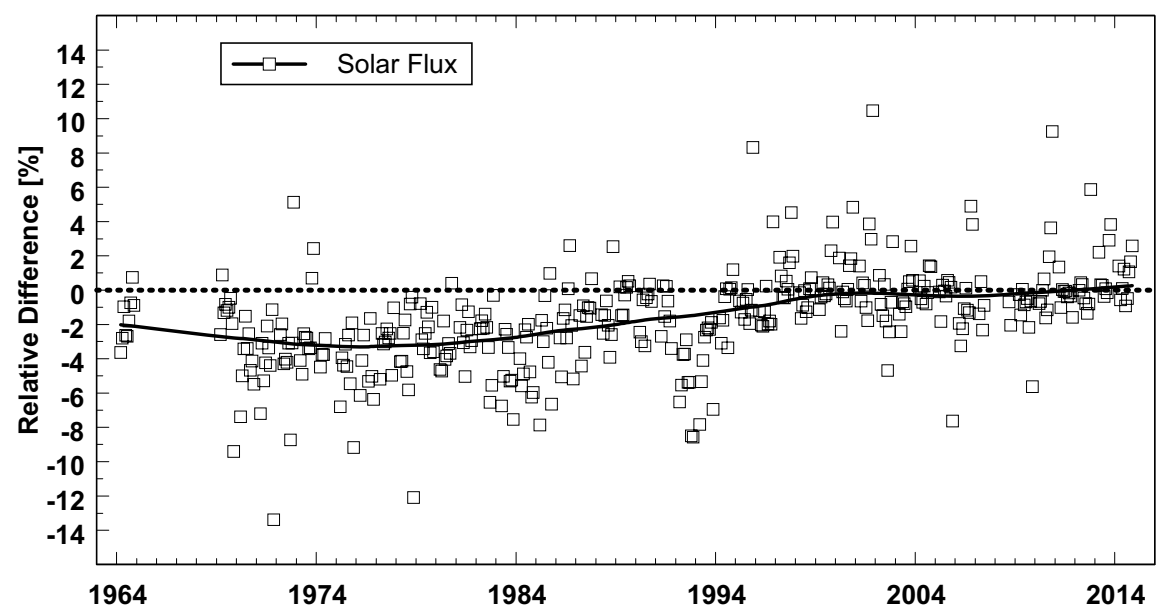

Fig. 8. The modelled (according Bird and Riordan 1986) monthly (MarchNovember) fractional deviations (open squares) of total solar irradiance ( 300$3000 \mathrm{~nm}$ ) for the period 1964-2014 and the pertaining smoothed values by LOWES smoother (solid curve).

obtained mean parameter values are: single scattering albedo (SSA) of 0.941 , asymmetry factor of 0.662 and Ångström exponent of 1.48 .

The mean AOT at $500 \mathrm{~nm}$ of 0.191 is obtained by averaging the CIMEL observations for the March-November season in the 2004-2014 period. This value represents the AOT benchmark used to calculate the relative change in the period 1964-2014 for the total solar energy flux at the ground level in the individual months. Only the period between March and November is considered for each year in order to minimize the effects of high uncertainties associated with measuring the Linke turbidity factor during low solar elevation angles. Finally a smoothing algorithm is applied to reveal the trend. The obtained results are depicted in Fig. 8.

A total change of approximately 3\% for the period 1970- 2014 is observed. A "dimming" event, associated with the Mt. Pinatubo volcanic eruption of 1991 is seen in the following two years. As previously mentioned, the "dimming-brightening transition" may be observed at Belsk around 1974 compared to 1980 in Western Europe. A similar trend overturning was found by Wild (2008) in a simulation conducted for the high latitude $\left(60^{\circ} \mathrm{N}-90^{\circ} \mathrm{N}\right)$ surface solar radiation anomalies but he found the observed dimmingbrightening transition in Western Europe around 1980. A turbulent nature of the Polish economic and industrial growth during the Soviet and early postSoviet era may be a factor that distinguishes the country from its western neighbours, which were developing in a more steady manner. 


\section{SUMMARY AND CONCLUSIONS}

The archived Linke turbidity factor and the surface water vapour pressure measurements are used to calculate the 40 -year long series of the broadband aerosol optical thickness at Belsk normalized to air mass equal to 2. The trend analysis of BAOT2 reveals a slight upward trend of $0.023 \pm 0.017(2 \sigma)$ per 10 years in the period of 1964-1975, next strong downward trend of $-0.051 \pm 0.017(2 \sigma)$ in the period 1976-1991, and since then a levelling off. Such a behaviour is possibly related to the economic changes in Poland in the last few decades. The local AOT maxima at Belsk are found in 1984 and 1992 due to the volcanic eruption of El Chichon and Mt. Pinatubo.

High correlation was found between the changes in the BAOT2 and concurrent AOT at $340 \mathrm{~nm}$ and at $500 \mathrm{~nm}$ measured by the CIMEL sun photometer in the period 2002-2012. This allows for the reconstruction of the historical AOT values, dating back to January 1964. The reconstructed AOT values are then used to calculate trends in the total solar radiation and its UV part at the ground level.

The aerosol changes cause $\sim 6 \%$ increase of UV index in the period 1974-1996 that is comparable with the ozone decline impact on UV in that period. Further increase of the surface clear-sky UV index at Belsk, related to the atmosphere "brightening", is unlikely in the next decades as it seems that the atmosphere aerosol loading in Poland reached the minimum level in the late 1990s. The modelled changes in the broadband $(\sim 300-3000 \mathrm{~nm})$ solar energy flux, which are calculated for clear-sky conditions using the reconstructed AOT at $500 \mathrm{~nm}$, show $\sim 3 \%$ increase of the clear sky total solar radiation in the period 1970-2000 that confirms the overall atmosphere "brightening" over Central Poland.

Acknowledgments. This work was partially supported by the National Science Centre granted on the basis of the decision number DEC2013/09/B/ST10/03553 and partially supported within statutory activities No. 3841/E-41/S/2015 of the Ministry of Science and Higher Education of Poland.

\section{References}

Bird, R.E., and C. Riordan (1986), Simple solar spectral model for direct and diffuse irradiance on horizontal and tilted planes at the Earth's surface for cloudless atmospheres, J. Clim. Appl. Meteorol. 25, 1, 87-97, DOI: 10.1175/15200450(1986)025<0087:SSSMFD>2.0.CO;2. 
Blumthaler, M., and W. Ambach (1988), Solar UVB-albedo of various surfaces, Photochem. Photobiol. 48, 1, 85-88, DOI: 10.1111/j.1751-1097.1988. tb02790.x.

Box, M.A., and A. Deepak (1978), Single and multiple scattering contributions to circumsolar radiation, Appl. Opt. 17, 23, 3794-3797, DOI: 10.1364/AO.17. 003794.

Chubachi, S. (1984), Preliminary result of ozone observations at Syowa station from February 1982 to January 1983, Mem. Nat. Inst. Polar Res. 34, 13-20.

Degünther, M., R. Meerkötter, A. Albold, and G. Seckmeyer (1998), Case study on the influence of inhomogeneous surface albedo on UV irradiance, Geophys. Res. Lett. 25, 19, 3587-3590, DOI: 10.1029/98GL52785.

Farman, J.C., B.G. Gardiner, and J.D. Shanklin (1985), Large losses of total ozone in Antarctica reveal seasonal $\mathrm{ClO}$ X/NO X interaction, Nature 315, 6016, 207-210, DOI: 10.1038/315207a0.

Grenier, J.C., A. De La Casinière, and T. Cabot (1994), A spectral model of Linke's turbidity factor and its experimental implications, Sol. Energy 52, 4, 303313, DOI: 10.1016/0038-092X(94)90137-6.

Holben, B.N., T.F. Eck, I. Slutsker, D. Tanré, J.P. Buis, A. Setzer, E. Vermote, J.A. Reagan, Y.J. Kaufman, T. Nakajima, F. Lavenu, I. Jankowiak, and A. Smirnov (1998), AERONET - A federated instrument network and data archive for aerosol characterization, Remote Sens. Environ. 66, 1, 1-16, DOI: 10.1016/S0034-4257(98)00031-5.

IGY (1958), Instruction Manual. Part VI, Radiation Instruments and Measurements, International Geophysical Year, Pergamon, London.

IPCC (2013), Summary for policymakers. In: T.F. Stocker, D. Qin, G.-K. Plattner, M. Tignor, S.K. Allen, J. Boschung, A. Nauels, Y. Xia, V. Bex, and P.M. Midgley (eds.), Climate Change 2013: The Physical Science Basis. Contribution of Working Group I to the Fifth Assessment Report of the Intergovernmental Panel on Climate Change, Cambridge University Press, Cambridge.

Jarosławski, J., and J.W. Krzyścin (2005), Importance of the aerosol variations for the surface UV-B level: Analysis of the ground-based data taken at Belsk, Poland, 1992-2004, J. Geophys. Res. 110, D16, D16201, DOI: 10.1029/ 2005/JD005951.

Jarosławski, J., J.W. Krzyścin, S. Puchalski, and P. Sobolewski (2003), On the optical thickness in the UV range: Analysis of the ground-based data taken at Belsk, Poland, J. Geophys. Res. 108, D23, 4722, DOI: 10.1029/ 2003JD003571.

Junker, C., and C. Liousse (2008), A global emission inventory of carbonaceous aerosol from historic records of fossil fuel and biofuel consumption for the period 1860-1997, Atmos. Chem. Phys. 8, 5, 1195-1207. 
Kannel, M., H. Ohvril, and O. Okulov (2012), A shortcut from broadband to spectral aerosol optical depth, Proc. Estonian Acad. Sci. 61, 4, 266-278, DOI: 10.3176/proc.2012.4.02.

Kaufman, Y.J., N. Gobron, B. Pinty, J.L Widlowski, and M.M. Verstraete (2002), Relationship between surface reflectance in the visible and mid-IR used in MODIS aerosol algorithm - theory, Geophys. Res. Lett. 29, 23, 2116, DOI: 10.1029/2001GL014492.

King, M.D., Y.J. Kaufman, D. Tanré, and T. Nakajima (1999), Remote sensing of tropospheric aerosols from space: past, present, and future, Bull. Am. Meteorol. Soc. 80, 11, 2229-2259, DOI: 10.1175/1520-0477(1999)080<2229: $\mathrm{RSOTAF}>2.0 . \mathrm{CO} ; 2$.

Krzyścin, J.W., B. Rajewska-Wiech, and J. Jarosławski (2013), The long-term variability of atmospheric ozone from the 50-yr observations carried out at Belsk (51.84 degrees N, 20.78 degrees E), Poland, Tellus B 65, 21779, DOI: 10.3402/tellusb.v65i0. 21779.

Linke, F. (1922), Transmissions-Koeffizient und Trubungsfaktor, Beitr. Phys. Fr. Atmos. 10, 91-103 (in German).

Markowicz, K.M., and J. Uscka-Kowalkowska (2015), Long-term and seasonal variability of the aerosol optical depth at Mount Kasprowy Wierch (Poland), J. Geophys. Res. Atmos. 120, 5, 1865-1879, DOI: 10.1002/ 2014JD022580.

Michalowska-Smak, A. (1981), Seasonal and secular changes of atmospheric turbidity in Warsaw and Belsk in the interval 1957-1980, Publs. Inst. Geophys, Pol. Acad. Sci. D-13, 149.

Mishchenko, M.I., B. Cairns, G. Kopp, C.F. Schueler, B.A. Fafaul, J.E. Hansen, R.J. Hooker, T. Itchkawich, H.B. Maring, and L.D. Travis (2007), Accurate monitoring of terrestrial aerosol and total solar irradiance: introducing the glory mission, Bull. Am. Meteorol. Soc. 88, 5, 677-692, DOI: 10.1175/ BAMS-88-5-677.

Ohvril, H., H. Teral, L. Neiman, M. Kannel, M. Uustare, M. Tee, V. Russak, O. Okulov, A. Joeveer, A. Kallis, T. Ohvril, E.I. Terez, G.A. Terez, G.K. Gushchin, G.M. Abakumova, E.V. Gorbarenko, A.V. Tsvetkov, and N. Laulainen (2009), Global dimming and brightening versus atmospheric column transparency, Europe, 1906-2007, J. Geophys. Res. 114, D10, D00D12, DOI: 10.1029/2008JD010644.

Ohvril, H., O. Okulov, H. Teral, and K. Teral (1999), The atmospheric integral transparency coefficient and the Forbes effect, Sol. Energy 66, 4, 305-317, DOI: 10.1016/S0038-092X(99)00031-6.

Pietruczuk, A. (2013), Short term variability of aerosol optical thickness at Belsk for the period 2002-2010, Atmos. Environ. 79, 744-750, DOI: 10.1016/ j.atmosenv.2013.07.054. 
Pietruczuk, A., and A. Chaikovsky (2012), Variability of aerosol properties during the 2007-2010 spring seasons over Central Europe, Acta Geophys. 60, 5, 1338-1358, DOI: 10.2478/s11600-012-0017-9.

Ruckstuhl, C., R. Philipona, K. Behrens, M.C. Coen, B. Dürr, A. Heimo, C. Mätzler, S. Nyeki, A. Ohmura, L. Vuilleumier, M. Weller, C. Wehrli, and A. Zelenka (2008), Aerosol and cloud effects on solar brightening and the recent rapid warming, Geophys. Res. Lett. 35, 12, L12708, DOI: 10.1029/ 2008 GL034228.

Stanhill, G., and S. Cohen (2001), Global dimming: A review of the evidence for a widespread and significant reduction in global radiation with discussion of its probable causes and possible agricultural consequences, Agr. Forest Meteorol. 107, 4, 255-278, DOI: 10.1016/S0168-1923(00)00241-0.

Stern, D.I. (2005), Global sulfur emissions from 1850 to 2000, Chemosphere 58, 2, 163-175, DOI: 10.1016/j.chemosphere.2004.08.022.

Streets, D.G., F. Yan, M. Chin, T. Diehl, N. Mahowald, M. Schultz, M. Wild, $\mathrm{Y}$. Wu, and C. Yu (2009), Anthropogenic and natural contributions to regional trends in aerosol optical depth, 1980-2006, J. Geophys. Res. 114, D10, D00D18, DOI: 10.1029/2008JD011624.

Uscka-Kowalkowska, J. (2013), An analysis of the extinction of direct solar radiation on Mt. Kasprowy Wierch, Poland, Atmos. Res. 134, 1, 175-185, DOI: 10.1016/j.atmosres.2013.08.002.

Weller, M., and U. Leiterer (1988), Experimental data on spectral aerosol optical thickness and its global distribution, Beitraege zur Physik der Atmosphaere 61, 2, 1-9.

Wild, M. (2008), Global dimming and brightening: A review, J. Geophys. Res. 114, D10, DOI: 10.1029/2008JD011470.

WMO (2011), Scientific assessment of ozone depletion: 2010. Global Ozone Research and Monitoring Project Report No. 52, World Meteorological Organization, Geneva, Switzerland.

Zhao, T.X.-P., I. Laszlo, W. Guo, A. Heidinger, C. Cao, A. Jelenak, D. Tarpley, and J. Sullivan (2008), Study of long-term trend in aerosol optical thickness observed from operational AVHRR satellite instrument, J. Geophys. Res. 113, D7, D07201, DOI: 10.1029/2007JD009061. 